\title{
The Potential of Plastic Reuse for Manufacturing: A Case Study into Circular Business Models for an On-Line Marketplace
}

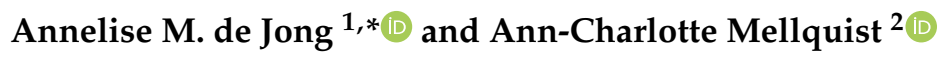 \\ 1 Sustainable Consumption and Resource Flows, IVL Swedish Environmental Research Institute, \\ Valhallavägen 81, 11428 Stockholm, Sweden \\ 2 Sustainable Business, RISE AB, Kistagången 16, 16426 Kista, Sweden; ann-charlotte.mellquist@ri.se \\ * Correspondence: annelise.dejong@ivl.se
}

\section{check for}

updates

Citation: de Jong, A.M.; Mellquist, A.-C. The Potential of Plastic Reuse for Manufacturing: A Case Study into Circular Business Models for an On-Line Marketplace. Sustainability 2021, 13, 2007. https://doi.org/ $10.3390 /$ su13042007

Received: 20 January 2021

Accepted: 6 February 2021

Published: 13 February 2021

Publisher's Note: MDPI stays neutral with regard to jurisdictional claims in published maps and institutional affiliations.

Copyright: (c) 2021 by the authors. Licensee MDPI, Basel, Switzerland. This article is an open access article distributed under the terms and conditions of the Creative Commons Attribution (CC BY) license (https:// creativecommons.org/licenses/by/ $4.0 /)$.

\begin{abstract}
The plastic industry is facing increasingly growing social and political demands on plastic recycling and reuse. The resource perspective is essential for plastic production companies. Circular economy is one perspective for how industries could deal with a lack of resources today and in the future. However, there are large challenges in the reuse of plastics waste, predominantly due to concern regarding the quality of the waste material. Our paper focuses on the potential of the exchange of plastic material waste between companies in the production process before it enters into the recycling loop. In this study our aim is to investigate if an on-line marketplace is relevant for the plastic industry for this exchange, the market potential and the potential business model and requirements of the marketplace. Through interviews and benchmarking with five platform providers and two plastic manufacturing companies, we collected information on the business models of international digital platforms and plastic manufacturers concerning the exchange of reusable materials between companies. We also collected data through a survey sent out to plastic manufacturers via two industry organizations in Sweden. This paper will present the results from the study and conclude with a description of draft requirements with particular focus on direct reuse of regrind material, and a potential business model for the on-line marketplace that should be run on a commercial basis. This study shows that there are opportunities for the plastic industry to be at the forefront of a circular initiative that could also be utilized by other industries with adjustments to reflect the specific requirements of each industry.
\end{abstract}

Keywords: plastic waste; circular economy; manufacturing industry; reuse; on-line marketplace

\section{Introduction}

Conservation of materials for reuse and recycling in the process industry is highly prioritized for reaching the Sustainable Development Goals. The plastic industry is facing increasing higher European targets for plastics recycling and reuse, which are calculated to be able to lead to substantial improvement of environmental and economic impacts [1]. In line with the implementation of the Green Deal strategy, aimed to transform the economy of the European Union into a modern, resource-efficient and competitive economy, several measures have been put into place to reach a more sustainable and circular production, of which the Circular Economy action plan was accepted in March 2020 [2]. The European Environment Agency (EEA) points at the potential for recycled plastics, as energy savings are significant, which also means that this is not only a profitable model for the plastic industry but can also give direct positive environmental benefits [3].

For this reason, we find it interesting and important to explore the potential for an on-line marketplace to facilitate resource efficiency and more circular plastic resource flows, and the appropriate business model for such a marketplace.

So, why is this not done on a larger scale? In the Nordic countries, a study of economic policy instruments revealed some obstacles for industrial plastic waste to be recycled to 
a higher degree [4]. According to Norden, part of the problem is that there is not a large enough economic potential for small and medium-sized producers of plastic to store waste material separately. The mixed plastic waste materials cannot be used directly in a new production of plastic products. At best, it is possible to use the material as packaging but typically it is handled as combustible waste. A quality guarantee of waste material is necessary to build trust when it comes to the quality of these material flows. Milios [5] states that a lack of information regarding quality and material properties increases the risk of high costs in markets for secondary materials in general. For our study this is important since it implies that direct reuse of materials would place even higher demands on the quality of materials. Additionally, European legislation regarding the quality of plastics is mentioned as a major obstacle for the reuse of plastics recommended by Economic Policy Instruments for plastic waste [4]. In a recent report on the climate effects of a circular economy [6] the case study on plastics claims that better functioning markets could reduce the risk for buyers and is an enabler for capturing the value in more circular value chains for plastics.

However, in order to make use of the potential of used material in the process industry, companies need to be able to gain access to those materials. Digitalization is on the rise in various areas for improving services and access to data in the public and private sector [7]. Emerging economic concepts, such as sharing economy and circular economy are reliant on the existence of platforms for bringing supply and demand together [8]. Here platforms for two-sided on-line marketplaces are useful to match and complete transactions of supply and demand in an on-line environment. The benefit lies in the interaction through a common platform with price models that appeal to both sides [9]. Fortuna and Diyamandoglu [10] distinguish between passive and active exchanges in an on-line marketplace where the active exchanges are facilitated by a broker whereas passive exchanges occur directly between donor and user. The structure and creation of such marketplaces in existing markets such as the process industry require different approaches and business models for companies operating there, which is challenging to define but could fruitfully be experimented within an agile development process [11]. In this paper we use the term "platform" for the wider concept of a system for different types of applications, while the term "on-line marketplace" is used for the digital platforms specifically aiming to match supply and demand of a good or a service.

Recently more attention is raised to the inherent paradox with design and producing material goods that is challenged by notions of overconsumption in relation to the environment and the planet boundaries. In response to this, new areas of sustainable design in relation to production have been shaped, for instance, by reducing the materials that are used in production or by creating services instead of products, which usually require new business models for manufacturing companies [12]. In this paper we present a Swedish feasibility study into the design of an on-line marketplace for reuse of plastic waste streams. The project was grounded in the concept of resource efficiency through a circular economy.

Plastic production in the world increased from 15 million ton in 1964 to 311 million tons in 2014 and is expected to double again by 2035 . Over $90 \%$ of the plastics manufactured today are made from crude oil, equivalent to $6 \%$ of world oil production, or equal to as much as the aviation industry uses globally [13]. Reusing existing plastic in new production chains is, from that perspective, an important part of being able to break this trend and both reduce waste and ensure that plastic is available as a material in the future.

The circular economy could be seen as a way of looking at resources from a practical, theoretical and philosophical perspective [14,15], with the ultimate goal of decoupling economic growth and environmental impact [16]. By adapting to new circular ways of managing resources, the predominantly linear resource depleting processes and structures of today's manufacturing industries could instead be shifting towards an industry of tomorrow. In accordance with the circular economy [17], waste should not exist but should be seen as a resource. Biological material can be composted, and the products of other material designed so that they can be: reused, refurbished, remanufactured and, ultimately, 
recycled. In summary, there is potential for increased resource efficiency through the collection and recirculation of high-quality plastic waste from producers of plastic products.

There is no single definition of a circular economy. In fact, Kirchherr et al. [18] reference up to 114 different definitions. They show that the circular economy is mostly depicted as a combination of reduce, reuse and recycle activities, and only to a smaller extent uses definitions that include systemic shifts. The authors of this paper acknowledge the fact that the level of resource efficiency needed for a truly long-term sustainable future will not be solved without systemic societal shifts, including areas such as consumer behavior, politics, economics and finance [19]. Nevertheless, the resource-based view on circular economy, based on reduce, reuse and recycle and on concepts like narrowing, slowing and closing material loops [20,21], zero waste or "waste is food" [17,22] remains an important part of the circular economy. It also helps businesses of today - which are operating in, and limited by, the systems of today-address immediate issues and reach concrete results [16] and further emphasize the need for concrete actions in areas such as structuring and organizing production and consumption systems, so that they can benefit from resource exchange. This study is grounded in the perspective of today's situation in the plastic industry. As long as the ambitions do not stop at this level, these efforts should be encouraged and seen as a good thing.

The potential for circulating plastic waste in the industry remains unreported so far, even though the volume of plastic waste streams in Sweden is quite extensive. The Swedish Environmental Emission Data organization (SMED) calculated this to be 560 Kton plastic waste from various industries and consumption waste, of which about 134 Kton originate from the manufacturing and service industry and thereof $27 \mathrm{Kton}$ are sorted plastic waste from the chemicals (plastic manufacturing) industry that can be reused [23]. In fact, about $34 \%$ of the plastic waste from the manufacturing industry (about $45 \mathrm{Kton}$ ) are brought back into the manufacturing loop (via some kind of recirculation) because of the high quality of waste material that is not deteriorated by ageing, and with proper information on content and type of plastic material. However, the study also indicated that these numbers are difficult to verify and the numbers on waste consisting of both combustible and mixed plastic types are missing.

In the Swedish industry, the need for adapting innovation management and business models to the digital age is imminent for optimizing production and material flows [24]. There are currently several international platforms for exchange of material that aim to exchange consumer and production waste, however there are no specific sites for professional users, which guarantee the quality of the material. Platforms are increasingly appearing in all sectors in Sweden and are being used for exchanging services and products in different sectors, however less so in the process industry [25]. This gap is further analyzed in this study. See Figure 1 for a simplified version of the circular economy framework. The framework presents several types of actors, including service providers (such as marketplaces), which could be a link between waste providers and production companies by offering collection, sorting, grinding and/or other types of waste transformation services.

We present a multidisciplinary study drawing from our own circular economy and sustainable design backgrounds, working together in the project with experts from the plastic industry. We will start by providing a short literature overview of the plastic waste streams and some of the barriers for reuse of plastic materials in manufacturing, followed by an overview of the circular economy and circular business models. In this study our research questions seek the answers to which types of material flows of plastic waste are relevant for an on-line marketplace and how the marketplace can be effectively positioned and operated in the market.

For the purpose of this paper, it is important to define and separate different types of reused plastic materials included in the project, see Table 1 and for some examples Figure 2. Here we will take a plastic product manufacturer's perspective, since we are not taking the post-consumer loop into account in this study. The defined types of materials 
in Table 1 can be the result of different types of reuse. Therefore, in this paper, the words reuse and recirculate are used in a broader sense.

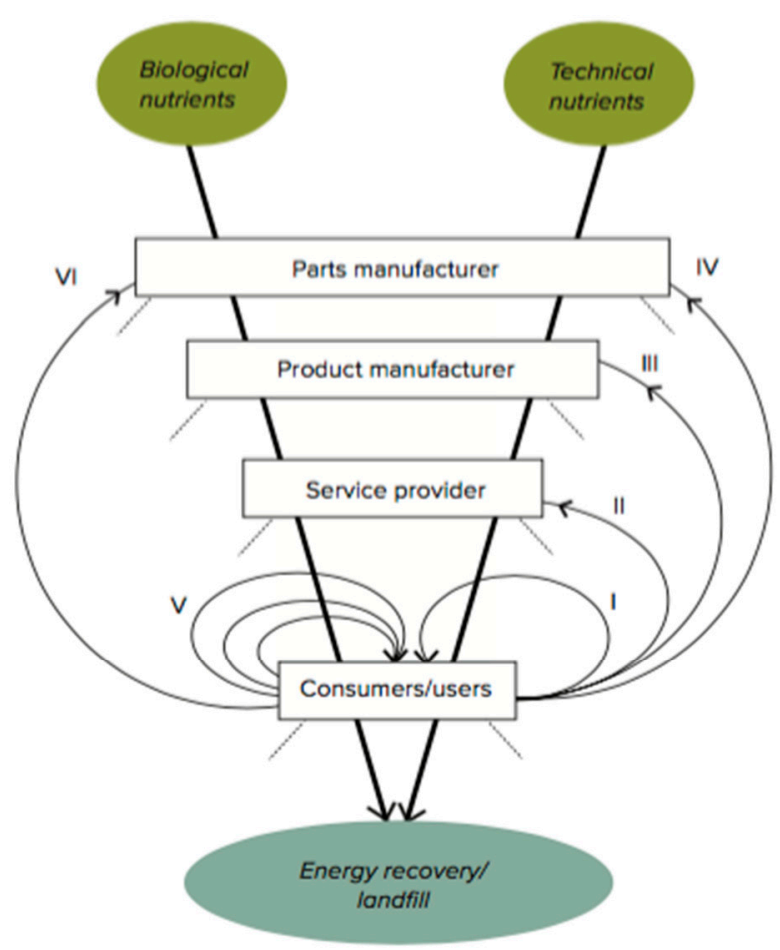

\author{
I: Repair \& maintenance \\ II: Reuse \& redistribution \\ III: Refurbishment \& remanufacturing \\ IV: Recycling \\ V: Cascading \& Repurposing \\ Vl: Biochemical feedstock extraction
}

Losses occuring between use leve/s and in

loop-closing

Figure 1. Simplified circular economy framework, based on [17].

Table 1. Our definitions of reused plastic material.

\begin{tabular}{cc}
\hline Material Type & Internal or External Source \\
\hline Virgin raw material & External (from plastics manufacturer) \\
Recycled material & External (from recycler) \\
Regrind material & External or internal (in case the plastic product \\
manufacturer has a grinding machine) \\
Whole components/parings & External or internal \\
\hline
\end{tabular}
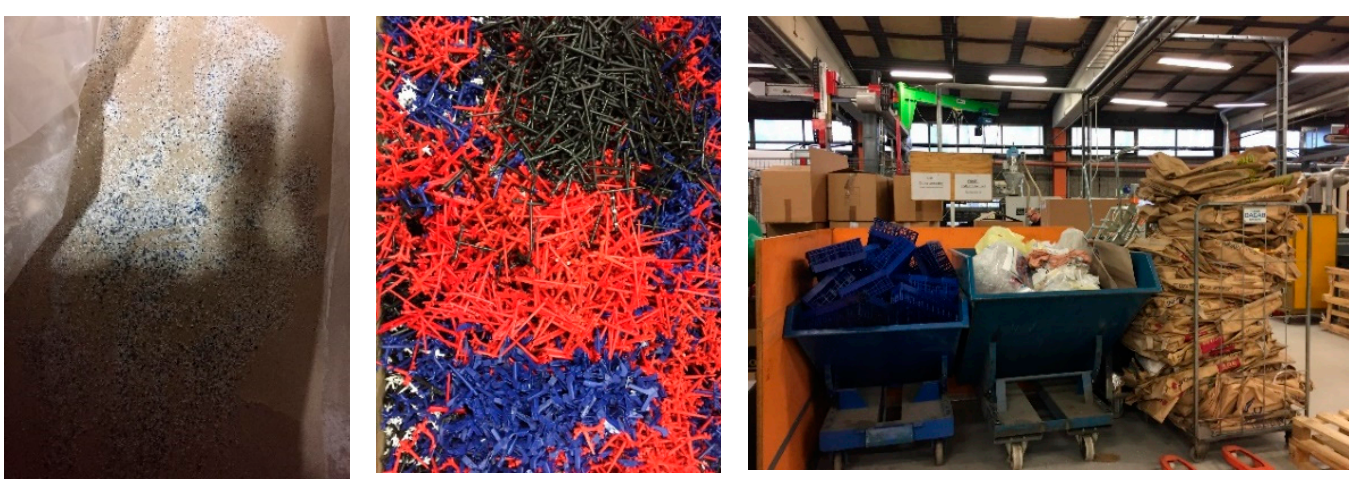

Figure 2. Regrind material (left), whole components (middle) and waste sorting facilities (right) of a plastic product manufacturer in the project.

The project set out to enable as much resource efficiency as possible, hence targeting whole components and parings and regrind rather than recycling. This is in line with 
the inherent higher energy and value saving potential of inner compared to outer loops according to, for example EMF, Niaounakis and Lüdeke-Freund et al. [17,25,26].

\section{Materials and Methods}

The study was organized as a feasibility study for an on-line marketplace for industrial plastic waste material, thus we reported here on the first explorative stages of the development process to identify suitable plastic waste material loops for exchange between actors, and appropriate markets and business models for the platform. To achieve this, we applied various data collection methods in two phases: an analytical and a generative phase, which were not chronologically separated but for a large part parallel and overlapping in time, due to the short project period of eight months in 2016-2017. After the project, follow-up projects were carried out and the authors contributed to supporting and analyzing the set-up of existing and new platforms both in Sweden and abroad, which will be taken up in the Discussion. The analytical phase consisted of desktop studies of functionalities of current marketplaces and a survey analysis of relevant material types indicated by the industry. The generative phase consisted of explorations of potential functions of the marketplace and possible appropriate business models for it. In order to do this, we set up our generative investigation in close cooperation with the project group. We will explain our approaches in the analytical and generative phase in more detail.

\subsection{Analytical Phase}

A survey was designed to be sent out to Swedish companies connected to the two largest Swedish industry organizations of plastic and chemical manufacturers and included questions such as the type and size of the company, plastic production, types and volumes of waste streams, the types and volumes of recirculation of material and acquisition and deposit means of waste material. The questions were of multichoice type with additional follow up questions to support the answer. We used Survey monkey software to collect the responses and to analyze the survey. Due to confidentiality issues, one industry organization decided that they would not send out the survey, instead they contacted a smaller number of their members by phone and asked all the questions from the survey, resulting in 14 filled-out surveys. At a later stage, another industry organization, with approximately 100 larger member companies, however not all being from the plastic industry, did send out the survey to all of their members and received three responses. The answers from these three surveys have also been included in the analysis but have not been counted in the response rate.

Thus, a total of 17 surveys were received and analyzed, but since the responses were anonymous we could not check the representativeness of the respondents. It should be noted that the response rate based on the initial industry organization was low with $15 \%$ thus indicating that the results could not be generalized but should be seen as indicative for further research.

In addition, the project reviewed existing on-line platforms with different functionalities for reusing and recycling materials, in order to make a gap analysis of the project's identified requirements. The selection was initially based on the research team's knowledge within circular economy, human-computer interaction, business models and design. The selection was widened through snowball sampling, for example by following up leads from seminars and fairs in the plastic industry. One platform that was mentioned in the project was no longer functional, but we did include the platform in the analysis since the information on the deployment of the platform was valuable for our study. Here the intention was to capture a few platforms to explore their functionality and set up, not to provide an exhaustive overview.

Data collection in the interviews was done through semi-structured interviews with initiators or operators of the different platforms with questions on the background and organization of the platform, the targeted materials and circular loops and customer 
segment, and on functional aspects of the platforms. Six platforms were analyzed by studying and self-use of the websites. The results were anonymized:

- NL: a Dutch B2B and B2C platform for reuse of building materials and other materials;

- SE1: a Swedish platform for recycling and reuse of various materials;

- SE2: a Swedish intraorganizational platform for reuse;

- SE3: Sweden's largest platform for reuse;

- SE4: a former Swedish B2B platform for equipment and material reuse;

- DE: a German platform for plastic industry with information and exchange of plastic materials.

Platforms NL, SE1, SE2, and SE4 were additionally interviewed in the fall/winter of 2016 and early 2017, whereas SE3 and DE were approached through the project but were not available for interviews. For one of the platforms (SE2), the information was derived from an interview conducted in 2015 by one of the authors, and covered all the relevant information with questions on the business model and operation of the platform.

The interviews with the platform providers were documented in an Excel data sheet with a number of categories, i.e., material/product, type of loop, customer segment, payment model, matching functionality and technical platform solution. The research team analyzed the data and concluded on the two most important differentiating dimensions, which were then used in the gap analysis.

\subsection{Generative Phase}

The technological development of the on-line marketplace presented no major challenges, but instead we focused on the value creation of the service and barriers for using reused materials. We applied a participatory design approach for sketching a first concept of both the service and a complementary business model for acquiring reused plastic materials. We facilitated the development process by ensuring active participation of various actors from the industry to study the roles that actors can take. Furthermore, we facilitated the process by enabling stakeholders, as future users of the marketplace, to design conceptual ideas for the marketplace. This process has enabled both the stakeholders' and our own understanding of the purpose and positioning of such an on-line marketplace in the market.

First, we performed semi-structured interviews with the participating plastic product manufacturers separately. The goal of the interviews was to start mapping out a potential business model for the platform provider. The interviewees were either CEO's or CFO's of the companies and the interviews were performed over the telephone and were approximately one hour each. In order to understand each company's own role in such a future exchange, and also the potential for the companies themselves to take on the role as a platform provider, the meetings started with mapping the current business models of the companies. All business model mapping and documentation were done in the format of the Business Model Canvas by Osterwalder and Pigneur [27], which is a way of documenting the organizational and financial architecture of a company. The business model canvas consists of nine different sections: The main section is the value proposition, which describes the value the company brings to its customers. The canvas then splits into two main parts: A right hand side-where the "how, what and why" of the customer is described in the sections of the customer segments, customer relations, channels and revenue streams-and a left hand side, where the "how and what" of the company's own work to deliver the value to the customer is described, in the sections of activities, resources, partners and cost structure.. Secondly, we applied the customer development method by Blank and Dorf [28], to create hypotheses for the future operations of the platform itself. The Customer Development Method explicitly describes the development of web/on-line based services, and we used sets of suggested questions to probe guesses and assessments of a potential business model of the platform.

In the project we ran one main generative focus group workshop with the participating Swedish companies: a large flooring manufacturer (organization A), a small injection mold- 
ing company (organization B), a municipal material lab (organization C) and an industry organization (organization D). This workshop was used to further assess the relevance of a platform for exchange of waste material in the Swedish plastic industry. In this workshop the requirements of the platform were discussed in two working groups, to allow all the participants' inputs to be accounted for. The setup of two groups was to create ideas for the type of information needed to purchase and offer reused material on the on-line marketplace, applying a design thinking approach [29] in which several potential ideas for the platform were sketched out. The materials used in this assignment were prelisted functionalities of the marketplace, which we showed directly in the workshop, such as organization and ownership, safety and privacy, storage and transport and financial transaction options. The resulting ideas for platform requirements were listed by the research team, and then categorized and summarized into a potential requirements list. In this workshop, the earlier created draft business models were also discussed and confirmed.

Finally, the study results from both phases, in terms of a rough draft of requirements and business model analysis were consolidated and brought up for discussion in a reference group meeting with representation from one of the analyzed platform providers (SE1), a waste company, a technological research organization, an environmental NGO and a design and engineering company. The meeting resulted in useful feedback on both the design requirements for the platform and the different business model concepts that we derived in the project. The feedback from this meeting was also integrated into the results and recommendations of the project.

\section{Results}

\subsection{The Relevance of and Requirements for a Platform}

Analysis of the survey showed that the amount of waste and the cost of handling these fractions differ significantly between companies. A third of the respondents indicate that no production waste material is recycled and over $80 \%$ of the respondents send production waste material to be incinerated.

The question as to the potential need for a flow of reused materials further showed that majority of the companies (59\%) already use recycled materials (at least their own waste) for production, however, most of the companies do not share their waste with other companies. The types of waste materials for reuse that are mostly mentioned are HDPE, LDPE, PP, PA6 and ABS. The reasons that companies indicated not using reused materials from others were a lack of required quality and traceability, thus resulting in mixed plastic materials, wrong size of material pellets and contamination of other materials, such as metals.

The questions as to the interest of companies and the perceived need for an exchange service revealed that despite the barriers for reusing materials that were mentioned earlier, some companies did already exchange materials with others. These were often part of a connected group of manufacturers, sometimes a holding, that already have established professional and sometimes personal connections. Still, majority (82\%) of both companies who have regular waste and those who do not have regular waste are interested in exchanging waste material from production with other companies that they are not familiar with. They particularly mention their interest in selling waste materials. Additionally, companies without costs for handling waste are also interested in an exchange platform.

At the workshop held with the project partners, the need for a platform was also expressed. Both organization A and organization B use their own waste material in production as much as possible. However, they also see a clear need for trading their waste material. The risk of low quality was also expressed as a major concern for the demand side of trading. At the workshop with the project participants, the four most important requirements of the on-line marketplace were identified:

- Credibility and security are central. There is a need for traceability and quality guarantee to purchase plastic waste via a platform. This could be provided via a 
certificate, but could preferably be "built in" to the platform via a warranty when using the platform and specifying the material.

- The platform needs to be simple and usable. It should save time compared to current processes (often very manual, trying to find buyers and traders via telephone or e-mail). Automatic matching of supply and demand would be the best solution for this. However, this would require a solid data specification.

- There is a need for more pull than push. At least one of the large manufacturers should participate in creating the "pull" effect. Possibly the platform should work at a national level. Transport costs were discussed but deemed to be of less importance compared to the relative value of the plastic waste.

- Added value could be generated by clearly communicating positive effects. There is an "upside" in being able to quantify an environmental effect and decreasing material cost, to be able to motivate the business and environmental case.

The group discussions resulted in a gross list of required material properties, which could both state the material clearly enough for quality warranty and allow for automatic matching of demand and supply. The list was consolidated in the net list seen in Table 2. The list can be seen as a rough draft of a possible data specification for a first platform prototype. This rough data specification was further discussed in the reference group workshop.

Table 2. Draft data specification.

\begin{tabular}{ccc}
\hline Order of Importance & Property Name & Sample Content \\
\hline 1 & Type of plastic & LDPE, PP, PVC \\
2 & Form of plastic & Regrind, regranulate, bale \\
3 & Clean production process & Yes, no \\
4 & Liquidity index & High, medium, low \\
5 & Volume & Metric tonnes \\
6 & Color & White, black, blue \\
7 & Packaging & Bag, box \\
8 & Price & SEK/kg \\
9 & Geography & Regions such as Stockholm, \\
10 & Frequency & Skåne \\
& &
\end{tabular}

\subsection{Market Potential}

The analysis of the two international and four Swedish on-line marketplaces for exchange of materials and/or products is depicted in Table 3. It shows a comparison of the type of material or product that is available on the platform, the customer segment that is targeted, and finally how it functions in terms of buying and selling. All investigated platforms allow users to swap, buy and sell used goods, products and waste, and thus are examples of circular material platforms. They differ primarily in which products/goods they handle and whether their customers are final consumers or manufacturing companies. While several material on-line marketplaces exist, there is no automatic matching or explicit quality checks on the materials. 
Table 3. Overview of functional and circular related aspects of two international and four Swedish on-line marketplaces for exchange of materials and/or products.

\begin{tabular}{|c|c|c|c|}
\hline Platform & Material/Product & Customer Segment & Functionality \\
\hline $\begin{array}{l}\text { NL: a Dutch B2B and B2C } \\
\text { platform for reuse of building } \\
\text { materials and other materials }\end{array}$ & $\begin{array}{l}\text { Primarily building materials } \\
\text { for reuse but also plastic } \\
\text { materials are included }\end{array}$ & $\begin{array}{l}\text { (Building) manufacturing } \\
\text { industry }\end{array}$ & $\begin{array}{l}\text { Advertisement-based for open } \\
\text { and closed groups, } \\
\text { notification needed to receive } \\
\text { further contact information }\end{array}$ \\
\hline $\begin{array}{l}\text { SE1: a Swedish platform for } \\
\text { recycling and reuse of various } \\
\text { materials }\end{array}$ & $\begin{array}{l}\text { All waste (incl. plastics). } \\
\text { Relative small volumes per } \\
\text { time (30\% from households) }\end{array}$ & $\begin{array}{l}\text { Households, recycling } \\
\text { industry, manufacturing } \\
\text { industry }\end{array}$ & $\begin{array}{l}\text { Requests can be sent in, } \\
\text { matched semi-automatically } \\
\text { with supply }\end{array}$ \\
\hline $\begin{array}{c}\text { SE2: a Swedish } \\
\text { intra-organizational platform } \\
\text { for reuse }\end{array}$ & $\begin{array}{c}\text { All products/surplus in an } \\
\text { organization (mostly office } \\
\text { equipment) }\end{array}$ & $\begin{array}{l}\text { Organizations in private and } \\
\text { public sector }\end{array}$ & $\begin{array}{l}\text { Automatic matching and } \\
\text { offers overview and reports of } \\
\text { transactions }\end{array}$ \\
\hline $\begin{array}{l}\text { SE3: Sweden's largest } \\
\text { platform for reuse }\end{array}$ & All products and services & Households and industry & Open advertisement market \\
\hline $\begin{array}{l}\text { SE4: a former Swedish B2B } \\
\text { platform for equipment and } \\
\text { material reuse }\end{array}$ & $\begin{array}{l}\text { Plastic waste-surplus waste } \\
\text { and also other materials } \\
\text { related to plastic } \\
\text { manufacturing e.g., pallets }\end{array}$ & Manufacturing industry & $\begin{array}{l}\text { Advertisement-based, } \\
\text { notification needed to receive } \\
\text { further contact information }\end{array}$ \\
\hline $\begin{array}{l}\text { DE: a German platform for } \\
\text { plastic industry with } \\
\text { information and exchange of } \\
\text { plastic materials }\end{array}$ & $\begin{array}{l}\text { Exchange and valuation of } \\
\text { plastic materials }\end{array}$ & $\begin{array}{l}\text { Plastic manufacturing } \\
\text { industry }\end{array}$ & $\begin{array}{c}\text { Advertisement based, } \\
\text { semi-automatic matching. }\end{array}$ \\
\hline
\end{tabular}

Of the platforms that we interviewed (NL, SE1, SE2 and SE4), we were able to retrieve some additional valuable insights on how the platforms were driven and organized around types of materials, products and customer segments, thus the strategy for attracting demand and supply:

- The Dutch platform (NL) originated as an idea in the 1990s from the owners of an architectural and construction company who started out by reusing materials, primarily wood, from demolished buildings. Initially they started a marketplace to offer the materials to other construction companies, but due to the low interest in reused materials at that time the materials were fed back into their own construction work. As interest was growing later on, they added a larger variety of types of building materials and specifications, and have expanded internationally and to other sectors as well. Recently, additional features were added, such as showing material flows, a library of projects and on the wish list are environmental effects, for example calculating reduced environmental impact. These have all added to the impact and attraction of the platform.

- $\quad$ SE1 is a company run by its owner who has a background in the recycling business. The company has grown substantially in later years and also started one subsidiary outside Sweden. The purpose of the platform was to reduce waste by offering a transparent way of finding interested customers. They mainly target the smaller fraction market, where both consumers and producers offer their waste on an ad hoc basis. Most customers are found in the recycling industry, but also among other manufacturing companies.

- $\quad$ SE2 is a software company, who sells licensed access to the platform software, which they have developed themselves. They thus operate as a "closed" marketplace within the organization that has decided to use the application. The initial idea was to offer a way to find use for the "functional surplus" that exists within an organization by helping to match supply and demand with advertisement and search functionality. The application is used by several large organizations in Sweden mainly for office 
furniture and office equipment, but could be used for any products, objects or even services within an organization.

- The former Swedish platform (SE 4) used for any type of material and equipment reuse was started by a plastic manufacturing company in 2008 for the plastic manufacturing industry but closed down in 2012 due to lack of time from those running it and a lack of demand for the service. The platform had grown from offering materials for reuse to everything that is lying "on the shelf" and that can be used by others. The required volumes of demand and supply seem to have been crucial here and were not sufficient to maintain the platform.

Many of the classifications were similar between the platforms and the research team identified that the two most differentiating dimensions were post-consumer vs. post-producer waste and manual vs. automatic mapping. The mapping of the different platforms along these dimensions resulted in the map shown in Figure 3. It suggests that there is a gap and a need for a new on-line marketplace, which would handle post-producer waste in an automatic way. This is a segment with important market potential.

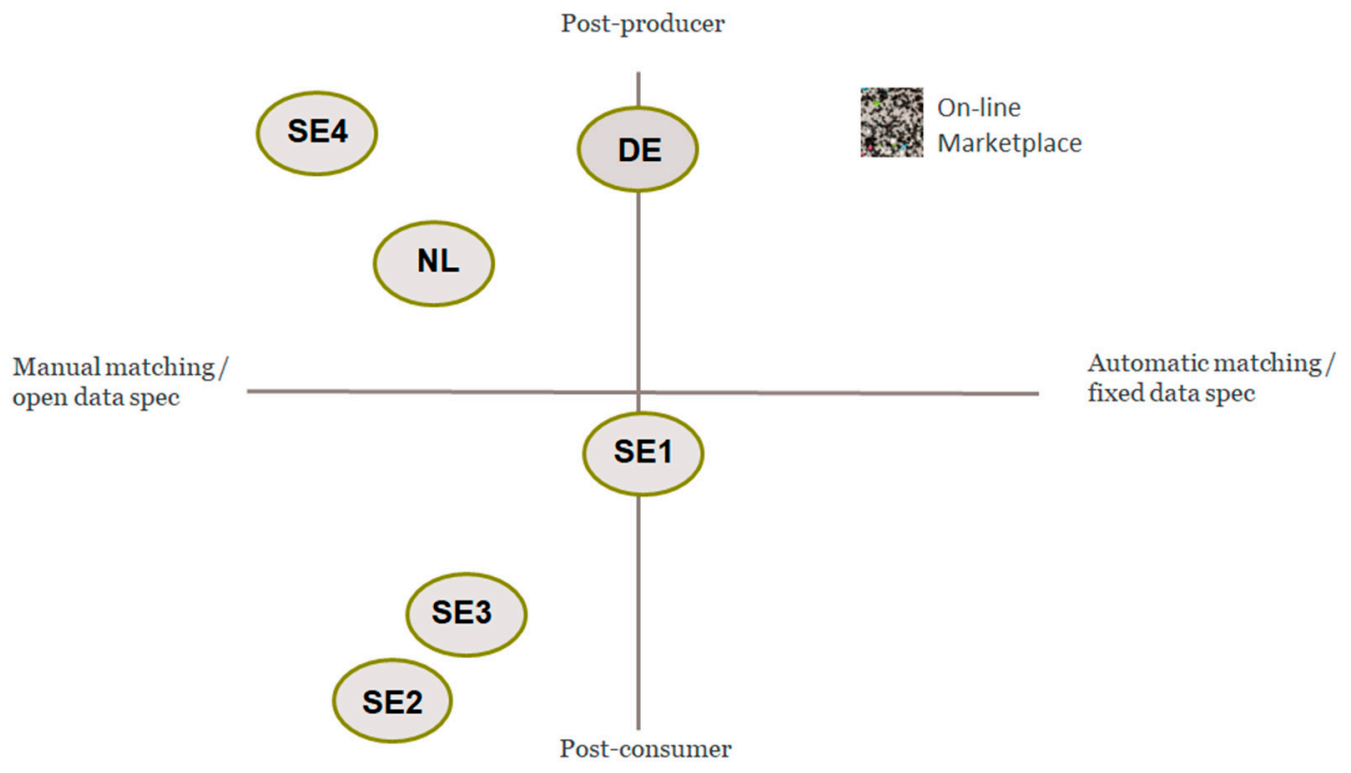

Figure 3. Gap analysis of platforms for material exchange.

\subsection{Appropriate Business Models}

In the interviews with the project partners, the current business models of the plastic product manufacturing companies (A and $\mathrm{B}$ ) and the industry organization (D) were discussed - both for the researchers to better understand the operations and to investigate the potential for each one of them to run the platform. Below is a description of the facts regarding current business models.

Both plastic product manufacturing companies are producers who primarily work according to linear sales models. Organization A is a leading producer of plastic flooring. Organization B sells different types of injection molded plastic products, including a fullservice offer from concept to post production treatment. Both companies reuse production waste in their own production when possible and use recycled material in their production to a small extent. Organization A has also tried a more innovative circular business model in terms of a lease of flooring to its customers, thereby ensuring that the flooring material gets back to them and can be used in new floor production. This is however still a marginal model with small turnover. The company sees a huge potential for using more external waste material in its production, as is the main focus of this project. Organization D has a business model based on membership fees, where they offer advice in legal and market 
affairs to their members. They do not handle plastic materials in their business, but they have a high level of knowledge in the plastic manufacturing industry.

Based on this, the project workshop also covered the different options for business models for a platform provider for the on-line marketplace. The research team analyzed the results and it was concluded that there were two principally different versions of the business model of the platform to discuss further:

- A for-profit model with a commercial owner and operator of the platform

- A not-for-profit model, with the industry organization or similar being the owner and driver of the platform.

Both versions would have the possibility to offer the functionality required (according to Section 3.1). Part of a business model is the revenue model i.e., how to get paid for the product or services by the users. A number of different revenue models were also identified in the interviews and in the project workshop. These included:

For the for-profit model:

- Advertisement fee (normally fixed price);

- Transaction fee at closed deal (fixed fee or percentage could also be set at an auction);

- Fee for supply information (sold to a limited number of interested customers);

- License fee (per time period), for the use of the platform application.

For the not-for-profit model:

- Free service. No transaction cost. The value for the platform provider lies in strengthening either its offer to members (i.e., for the industry organization) or in systematically simplifying and making their own business more efficient (i.e., for a larger plastic manufacturer).

As a next step, the two types of business models (the for-profit and the not-for-profit model) including revenue models were presented and discussed in a reference group meeting. The reference group agreed that the risk of negligence and slow responsiveness to market needs would be substantially larger if the platform was run on a not-for-profit basis. The commercial set up is seen as a warranty for professionalism and efficiency. It was also deemed necessary that the platform owner has very good knowledge of plastics chemistry and plastics materials in general to ensure a solution to the quality issues. The conclusion after the final workshop with the reference group was that the platform should be run on a commercial basis. The choice was based on the finding that the platform that had not been successful (SE4) had been run on spare-time and more idealistic basis, while the platforms still in operation were all run on a commercial basis. Regarding the revenue model, the reference group meeting concluded that this is something that could be tried out in practice during testing. It was suggested, however, that a transaction-based payment would be the best starting point for further development, due to simplicity and transparency.

The preferred business model agreed on after the reference group meeting is shown in Figure 4, which should be seen as a first draft business model.

The value proposition of the recommended business model is "easy matching of supply and demand of plastic waste of different qualities, with quality guarantee". This value proposition is delivered to plastic manufacturing companies through an on-line marketplace. The customer relations could be both a short-term transactional relationship and more long-term stable relationships. The connections between supply and demand in the platform would initially be transactional and ad hoc but is expected to grow into more stable long-lived relationships between sellers, buyers and the platform owner. The more long-lived relations and efficient exchange between parties, the better for the circular outcome. The main internal resources and activities to provide this service consist of the technical solution for the platform, the skills to run and maintain it, and expertise in plastic material and competencies in marketing and sales. 


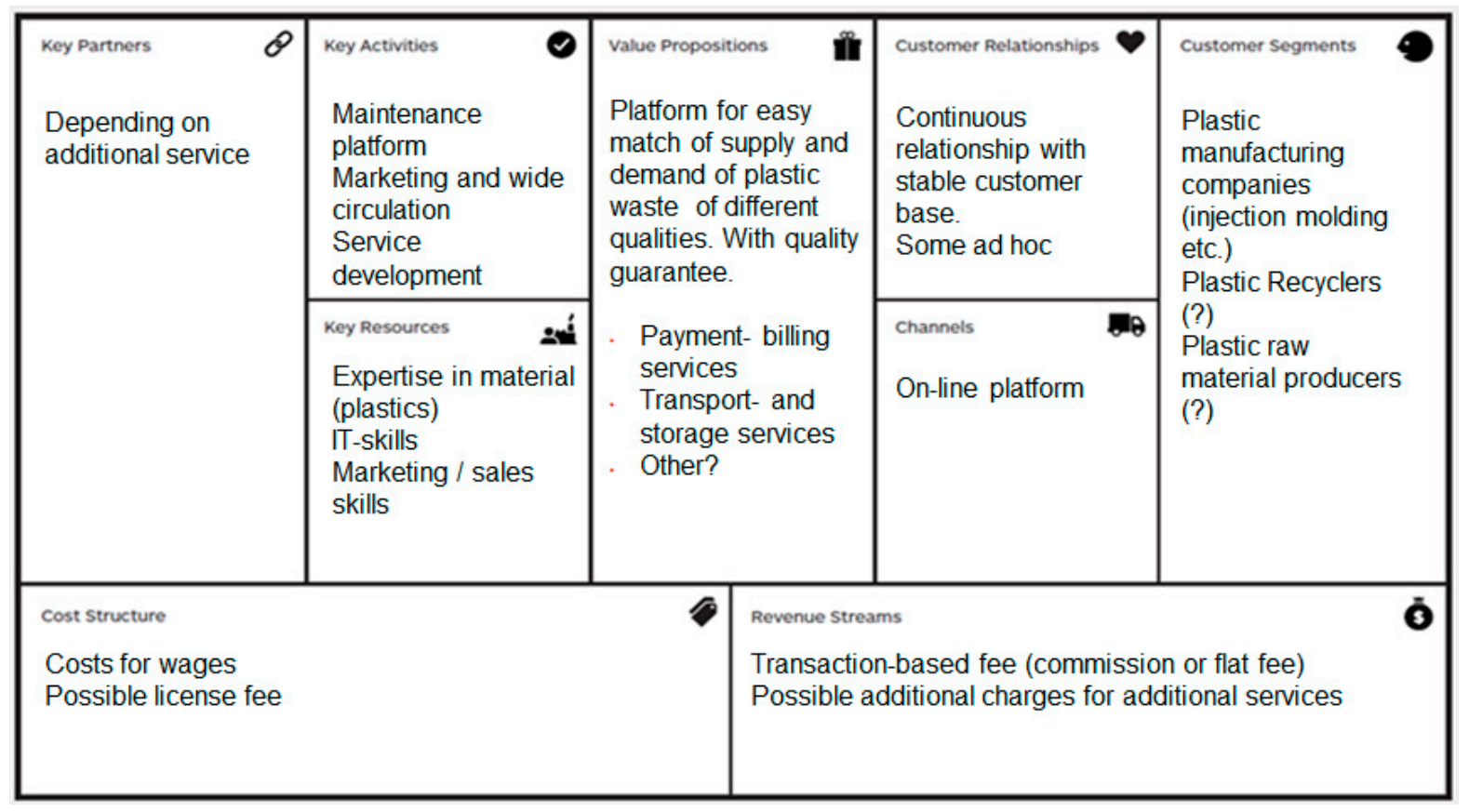

Figure 4. A first draft recommended business model for the on-line marketplace.

This draft business model, including the revenue model is a first tentative presentation, and should be further developed, detailed and tested. This could be done in a follow-up project or directly in the market.

\section{Discussion}

Despite practical barriers on material quality and volumes, there is potential for additional value preservation through exchange of waste material in the plastic industry, compared to other manufacturing industries. Many of the injection molding companies have a grinding machine, where plastic waste of different forms can be grinded to pellets like components, fit for the normal production line. In the context of the circular economy framework [17], this creates the opportunity of reusing post-industrial plastic waste for the production of plastic artifacts. The on-line marketplace could support both the reuse of plastic waste in an "as is" form and recycled waste material, but it could also support a loop between different plastic manufacturers, which would be less efficient and value preserving than reuse, but still more value preserving than a recycling loop, while offering the opportunity of more flexibility for the plastic manufacturer.

The business model canvas method was deployed in the project as a way of structuring and documenting the work. Since none of the actors in the project could-or would-take on the role as the owner of the on-line marketplace, the BMC results must be seen as a best guess hypothesis to be further developed in an agile process, as suggested by Björkdahl et al. [11]. Nevertheless, the project has resulted in some important findings regarding a potential business model for an on-line marketplace. The suggested business model is based on a commercial set up, where the platform provider sells its services to the users, i.e., the plastic industry actors. This is an example of a two-sided marketplace suitable for a circular economy [9] with active exchange of goods [10]. In a follow up project focused on the Swedish market, we analyzed a few new marketplaces that appeared in Northwest Europe with a focus on post-industrial plastic waste, and offering additional services including matchmaking and material quality certificates. The follow-up analysis did not contradict the findings of this paper, but rather confirmed them, since much industrial plastic waste is still occurring, which could be prevented by facilitating other actors to (re)use it. An estimate of the amount of the post-industrial plastic waste flows was calculated at 5000 ton per year in Sweden alone [30]. This indicates that the market 
has not changed that much and that the potential for redirecting these flows back into the loop still exists, including the application of a new business model by new actors.

As in all commercial contexts, the demand side of the marketplace is extremely important. For example, in the case of the Dutch platform, where a base demand was needed to make it feasible to take up used materials from other companies, a role that the platform owners took at first. When they started to work internationally, creating demand was in some cases accelerated by connecting professional matchmakers who worked locally with limited customers for the service. Additionally, companies that are situated in close geographical proximity, such as at industry zones, were initially targeted to reduce logistic complexity of exchanging materials. Today, several companies share material between each other, in so-called industrial symbioses where traditional industries in a collective approach to competitive advantage exchange physical materials, water, energy and/or byproducts, etc., based on geographical proximity [31].

It is also possible to extend the customers to involve plastic recyclers. Although more issues of competitions could be foreseen, it also opens up the possibility to create a larger demand "pull", which has been deemed necessary for the success of the marketplace. Another, or additional, way of creating the "pull" effect would be to have one of the bigger manufacturers in the industry run the marketplace. This could involve a risk of bias in terms of fair competition though.

Based on the synthesis of our interviews and case studies with existing and closed platform providers, it seems that financing of the platforms through the start-up and growth phases will be a challenge that needs to be managed in parallel to developing the most applicable business and revenue models in follow up-phases.

Obviously, this study is a first exploration of the field of plastic waste material from manufacturers and has important limitations regarding methods applied and selection of the participants. The results of this study were based on a limited number of companies interviewed and responding to the survey, which were probably triggered by the possibility to improve reuse of waste since they were part of the project. Limitations of methods include the way the platforms were selected by means of ad-hoc discussions at seminars and fairs and with the participating industry organizations. Another important limitation concerns the way only companies selected by the industry organization were contacted and therefore were possibly positive-minded towards reuse of waste in their response.

The design approach resulted in active participation of the companies in the project groups who were perhaps not really used to these creative sessions but nevertheless brought their knowledge and experience into the discussions. Due to the short period of the study, we were not able to prototype and try out the design of the service or the business model but still the conceptualization of the service and business model brought the actors around the table to discuss barriers around reusing materials and share ideas about opportunities and potential. In this process we applied traditional data collection methods such as interviews, observations and questionnaires, which are familiar to any other social discipline, such as psychology or engineering. As Koskinen et al. write [29] (p. 126) the difference is that "Designers are expected to imagine new things, not to study what exists today". Additionally, as they further point out, designers have to find the right vocabulary and ways to make people imagine through methods for "stretching the context rather than describing it." (ibid.). This is how we worked with the project group, by gathering people with different expertise and backgrounds in a discussion, which we as researchers facilitated in order to cocreate new things. Our initial hope was that one of the larger plastic manufacturers would be interested to take a more active role as the owner or creating demand for the used materials, but we were not able to verify this, as the project duration was too short for implementing the marketplace.

Therefore, additional research is needed to reduce bias and increase response in various parts of the study, which means that the results should be analyzed with some caution. Future work should be aimed at determining the potential and the criteria for the exchange of plastic waste material in a larger sample than this study and selecting an 
adequate tool or platform for this purpose. At this stage the platform concept is focused on industrial waste and the possibilities of reusing waste materials that are still of high value. Still, we also foresee future varieties of this platform being used on post-consumer material such as plastics from the hospitals and beach waste, and informing and inspiring designing with materials from these tighter reuse loops.

\section{Conclusions}

There are currently several international and Swedish on-line marketplaces for exchange of material that aim to exchange consumer and production waste. However, most of these sites are targeted at consumers whereas this project was aimed at professional users. There are a few sites for professional users and for plastic material reuse that we found in this project and a follow up project. Only a few of the existing platforms offer quality guarantee or automatic matching, and this is the reason for the apparent strong market potential for the on-line marketplace for plastic production waste.

The aim of this paper was to investigate the relevance of an on-line marketplace to enable more recirculation of plastic materials within the plastic industry, and to understand the functional requirements and adequate business model for such a marketplace. Our main conclusions are:

- $\quad$ The on-line marketplace is relevant for the industry. Both the survey, interviews and the workshop results show that there is a broad interest and potential for more recirculation of plastic production waste in the industry.

- There is market potential for a marketplace that could provide automatic matching of supply and demand and a quality warranty for the materials traded through the platform. This could be solved by the use of a detailed data specification, and the project has provided a draft outline for this.

- Different business and revenue models are possible for the operation of the marketplace, and the final selection will be dependent on the designated owner. The recommendation from the project is to set out with a for-profit model with transaction-based payment, to ensure future development and competitiveness of the marketplace.

There is a need for increased circular thinking and action in all industries and this study shows that there are opportunities for the plastic industry to be at the forefront of a circular initiative that could also be utilized by more industries with adjustments to reflect the specific requirements of each industry.

Author Contributions: Conceptualization, A.M.d.J. and A.-C.M.; methodology, A.M.d.J. and A.-C.M.; formal analysis, A.M.d.J. and A.-C.M.; investigation, A.M.d.J. and A.-C.M.; writing-original draft preparation, A.M.d.J. and A.-C.M.; writing-review and editing, A.M.d.J. and A.-C.M.; visualization, A.M.d.J. and A.-C.M.; supervision, A.M.d.J.; project administration, A.M.d.J.; funding acquisition, A.M.d.J. All authors have read and agreed to the published version of the manuscript.

Funding: This research was funded by Sweden's Innovation Agency (Vinnova), grant number 2016-03844.

Institutional Review Board Statement: "Not applicable" for studies not involving humans or animals.

Informed Consent Statement: Informed consent was obtained from all subjects involved in the study.

Acknowledgments: First we would like to acknowledge our partners in the project as well as all contributing companies to the survey. Finally, many thanks to our former colleagues, in particular Elin Önnevall for initiating the project and co-authoring earlier versions of this paper, and Lizette Reitsma for creating the circular economy framework image and reviewing this paper.

Conflicts of Interest: The authors declare no conflict of interest.

\section{References}

1. Hestin, M.; Faninger, T.; Milios, L. Increased EU Plastics Recycling Targets: Environmental, Economic and Social Impact Assessment; Final Report for Plastic Recyclers Europe; BIO by Deloitte for Plastic Recyclers Europe: Brussels, Belgium, 2015. 
2. European Parliament. EU Circular Economy Action Plan: A New Circular Economy Action Plan for a Cleaner and More Competitive Europe. Available online: https:/ / ec.europa.eu/environment/circular-economy/ (accessed on 30 December 2020).

3. De Schoenmakers, M.; Gillabel, J. Circular by Design. Products in the Circular Economy; EEA Report no 6/2017; European Environment Agency: Copenhagen, Danmark, 2017; ISSN 1977-8449.

4. Hennlock, M.; zu Castell-Rüdenhausen, M.; Wahlström, M.; Kjær, B.; Milios, L.; Vea, E.; Watson, D.; Hanssen, O.J.; Fråne, A.; Stenmarc, Å.; et al. Economic Policy Instruments for Plastic Waste; TemaNord 2014:569; Nordic Council of Ministers: Copenhagen, Danmark, 2014

5. Milios, L. Advancing to a Circular Economy: Three essential ingredients for a comprehensive policy mix. Sustain. Sci. 2018, 13, 861-878. [CrossRef] [PubMed]

6. Enkvist, P.-A.; Klevnäs, P. The Circular Economy. A Powerful Force for Climate Mitigation. Transformative Innovation for Low-Carbon and Prosperous Industry. Available online: http:/ / materialeconomics.com/publications/the-circular-economy (accessed on 10 June 2018).

7. Wiewiórowska-Domagalska, A. Online Platforms, How to Adopt Regulatory Framework to the Digital Age? IMCO-2017-01, PE 607.323, Mariusz Maciejewski EN Policy Department A: Economy and Scientific Policy; European Parliament: Brussels, Belgium, 2017.

8. de Bas, P.; Batura, O.; Yagafarova, A.; van Gorp, N.; Kesler, R.; Laitenberger, U.; Pichler, E. Business to Business Relations in the Online Platform Environment; Final report FWC EENTR/300/PP/2013/FC-WIFO; European Commission, Directorate Generale for the Internal Market, Industry, Entrepreneurship and SME's: Brussels, Belgium, 2017.

9. Rochet, J.-C.; Tirole, J. Platform Competition in Two-Sided Markets. J. Eur. Econ. Assoc. 2003, 1, 990-1029. [CrossRef]

10. Fortuna, L.M.; Diyamandoglu, V. NYC WasteMatch-An online facilitated materials exchange as a tool for pollution prevention. Resour. Conserv. Recycl. 2015, 101, 122-131. [CrossRef]

11. Bjorkdahl, J.; Wallin, M.W.; Kronblad, C. Digitalisering—Mer an Teknik. Kartlaggning av Svensk Forskning Ochna Ringslivets Behov; Serie: Vinnova Rapport VR 2018:06; Swedish Governmental Agency for Innovation Systems: Stockholm, Sweden, 2018.

12. Bakker, C.A.; Den Hollander, M.C.; Van Hinte, E.; Zijlstra, E. Products That Last_Product Design for Circular Business Models, 1st ed.; TU Delft Library/Marcel den Hollander IDRC: Delft, The Netherlands, 2014.

13. EMF: Ellen MacArthur Foundation. The New Plastics Economy: Rethinking the Future of Plastics; Ellen MacArthur Foundation: Cowes, UK, 2016.

14. Mangan, A. The Circular Economy: The Start of an Economic Revolution or Just the Latest Business Buzzword? In 3BL Media. 2015. Available online: http:/ /3blmedia.com/News/Circular-Economy-Start-Economic-Revolution-or-Just-Latest-BusinessBuzzword (accessed on 14 September 2017).

15. Joce, C. Circular economy: Corporate buzzword or real opportunity? In Cambridge Consultants; 2017; Available online: http:/ / blog.cambridgeconsultants.com/circular-economy-corporate-buzzword-or-real-opportunity/ (accessed on 14 September 2017).

16. Ghisellini, P.; Cialani, C.; Ulgiati, S. A review on circular economy: The expected transition to a balanced interplay of environmental and economic systems. J. Clean. Prod. 2016, 114, 11-32. [CrossRef]

17. EMF: Ellen MacArthur Foundation. Towards the Circular Economy, Volume 1, Economic and Business Rationale for an Accelerated Transition; Ellen MacArthur Foundation: Cowes, UK, 2013.

18. Kirchherr, J.; Reike, D.; Hekkert, M. Conceptualizing the circular economy: An analysis of 114 definitions. Resour. Conserv. Recycl 2017, 127, 221-232. [CrossRef]

19. Raworth, K. Doughnut Economics Seven Ways to Think Like a 21st-Century Economist. In Random House Business Books; Chelsea Green Publishing: White River Junction, VT, USA, 2017.

20. Stahel, W.R. The Performance Economy; Palgrave Macmillan: Basingstoke, UK; New York, NY, USA, 2010.

21. Bocken, N.M.P.; de Pauw, I.; Bakker, C.; van der Grinten, B. Product design and business model strategies for a circular economy. J. Ind. Prod. Eng. 2016, 33, 308-320. [CrossRef]

22. McDonough, W.; Braungart, M. Cradle to Cradle: Remaking the Way We Make Things; Vintage: London, UK, 2009.

23. Svensk MiljöEmissionsData (SMED). Kartläggning av Plastavfallsströmmar i Sverige; Rapport nr 108; Sveriges Meteorologiska och Hydrologiska Institut: Norrköping, Sweden, 2012; ISSN 1653-8102.

24. Chertow, M. Industrial Symbiosis, Literatur and Taxonomy. Annu. Rev. Energy Environ. 2000, 25, 313-337. [CrossRef]

25. Niaounakis, M. Biopolymers Reuse, Recycling, and Disposal; Plastics Design Library Handbook Series; Elsevier: Amsterdam, The Netherlands, 2013.

26. Lüdeke-Freund, F.; Gold, S.; Bocken, N. A Review and Typology of Circular Economy Business Model Patterns. J. Ind. Ecol. E-pub ahead of print. 25 April 2018. Available online: http:// portal.research.lu.se/portal/en/publications/a-review-and-typology-ofcircular-economy-business-model-patterns(1601abad-22e3-4f26-b6da-75784aa20de2).html (accessed on 24 May 2018).

27. Osterwalder, A.; Pigneur, Y. Business Model Generation: A Handbook for Visionaries, Game Changers, and Challengers; Wiley: New Jersey, NY, USA, 2010.

28. Blank, S.; Dorf, B. The Startup Owner's Manual, Vol 1 The Step-by-Step Guide for Building a Great Company; K\&S Ranch Publishing: Pescadero, CA, USA, 2012.

29. Koskinen, A.; Zimmerman, J.; Binder, T.; Redstrom, J.; Wensveen, S. Design Research through Practice: From the Lab, Field, and Showroom; Elsevier: Amsterdam, The Netherlands, 2011. 
30. SMED. Kartläggning av Plastflöden i Sverige: Råvara, Produkter, Avfall och Nedskräpning; Sveriges Miljö Emissions Data, Rapport Nr 01 2019; Sveriges Meteorologiska och Hydrologiska Institut: Norrköping, Sweden, 2019; In Swedish.

31. Bocken, N.M.P.; Short, S.W.; Rana, P.; Evans, S. A literature and practice review to develop sustainable business model archetypes. J. Clean. Prod. 2014, 65, 42-56, ISSN 0959-6526. [CrossRef] 